\title{
Memória Organizacional na Ciência da Informação: desvendando relações com o Conhecimento Organizacional
}

\author{
Rayan Aramís de Brito Feitoza \\ Mestrando; Universidade Federal da Paraíba; João Pessoa, PB, Brasil \\ rayanbritof@gmail.com \\ Laiana Ferreira de Sousa \\ Doutoranda; Universidade Federal da Paraíba; João Pessoa, PB, Brasil \\ laih.fsousa@gmail.com \\ Ilka Maria Soares Campos \\ Doutoranda; Universidade Federal da Paraíba; João Pessoa, PB, Brasil \\ ik.campos@uol.com.br \\ Emeide Nóbrega Duarte \\ Doutora; Universidade Federal da Paraíba; João Pessoa, PB, Brasil \\ emeide@hotmail.com
}

Resumo: Este trabalho busca analisar os conceitos de Memória Organizacional por meio da produção científica publicada na Base de Dados de Periódicos em Ciência da Informação, com o intuito de entender suas relações com o Conhecimento Organizacional. Metodologicamente, caracteriza-se como uma pesquisa documental do tipo exploratória e descritiva com abordagem qualiquantitativa. Para análise e organização dos dados foi utilizada a análise de conteúdo enquanto método de procedimento, seguindo a técnica de análise temática, considerando: os autores que mais se destacaram na produção de pesquisas sobre a temática, distribuição de artigos de periódicos sobre Memória Organizacional por ano, periódicos indexados na base citada com publicações de artigos sobre o tema, principais palavras-chave abordadas pelos trabalhos analisados e, por último, a análise dos conceitos sobre Memória Organizacional para o entendimento de suas relações com Conhecimento Organizacional. Os resultados permitem inferir que houve um aumento no interesse por estudar a estrutura organizacional das empresas, evidenciando a necessidade de expandir as pesquisas envolvendo a cultura e memória das organizações. A pesquisa possibilitou verificar também que os conceitos de Memória Organizacional apresentam relações dialógicas com o Conhecimento Organizacional, permitindo concluir que possuem correlações nos sentidos metodológicos, conceituais e práticos.

Palavras-chave: Memória organizacional. Conhecimento organizacional.

Produção científica. Ciência da Informação. 


\section{Introdução}

A ciência da informação, por ser uma ciência de natureza interdisciplinar (SARACEVIC, 1996), aborda diversas temáticas estudadas não apenas neste campo científico, mas também em diversas áreas de conhecimento, dentre elas, a memória.

Araújo (2017, p. 22) alerta para o fato de que a "Memória [...] sempre esteve presente no campo da ciência da informação.”, o autor acredita que a temática vem sendo trabalhada nas duas últimas décadas e vem destacando-se em linhas de pesquisas nos programas de pós-graduação.

A memória pode ser entendida em vários aspectos, como: individual, coletiva, social, institucional e organizacional. Assim, pode ser trabalhada no campo da Ciência da Informação (CI) dependendo da perspectiva do estudo. A abordagem deste trabalho está centrada na Memória Organizacional (MO), tendo em vista que vem sendo estudada em algumas pesquisas do campo científico da CI com ênfase nas organizações ligando-se assim a uma das suas subáreas, chamada Gestão da Informação e do Conhecimento (ARAÚJO, 2014). No entanto, se faz necessária a compreensão do entendimento da MO e sua aplicação nestes estudos.

Sendo assim, a questão norteadora tem a seguinte formulação: Como se dá a produção científica na Ciência da Informação sobre Memória Organizacional e como seus conceitos podem estabelecer relações com o Conhecimento Organizacional? Diante disso, foi realizada uma pesquisa com o objetivo de analisar os conceitos de MO por meio da produção científica da CI, com o intuito de entender suas relações com o Conhecimento Organizacional.

Metodologicamente, caracteriza-se como uma pesquisa documental do tipo exploratória e descritiva com abordagem qualiquantitativa. Para análise e organização dos dados, foi utilizada a análise de conteúdo enquanto método de procedimento, seguindo a técnica de análise temática para realizar o levantamento de publicações sobre o referido assunto publicadas na Base de Dados de Periódicos em Ciência da Informação (BRAPCI). 


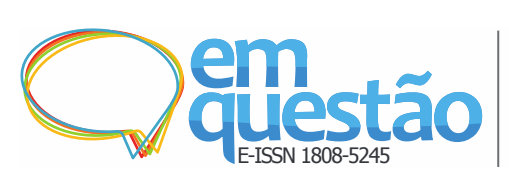

Memória Organizacional na Ciência da Informação: desvendando relações com o Conhecimento

Organizacional

Ryan Aramis de Brito Feitoza, Laiana Ferreira de Sousa, Ilka Maria Soares Campos e Emeide Nóbrega Duarte

A pesquisa justifica-se por se tratar de um tema pouco explorado na literatura da área e pela não identificação de estudo semelhante realizado na BRAPCI. Entender como vem sendo estudada a Memória Organizacional e como ela possui relações com o Conhecimento Organizacional por meio das produções científicas em alguns periódicos da área, poderá ocasionar reflexões aos pesquisadores que têm interesse pela temática e proporcionar tendências para a área do conhecimento.

\section{Memória e Memória Organizacional: reflexões e conceitos}

Antes de iniciarmos uma reflexão acerca dos conceitos e de como se configurase a Memória Organizacional, remetemos ao contexto da memória no sentido amplo, com o intuito de, mais adiante, entendermos melhor as características e funcionalidades no contexto das organizações.

Como dito anteriormente, a temática "memória" é estudada em diversas áreas de conhecimento, sendo compreendida a partir do seu contexto de aplicabilidade e/ou pesquisa com determinadas especificidades. Dentre os campos científicos que se apropriam de estudos voltados para a memória, há "Psicologia, Neurociência, História, Arqueologia, Administração, Sistemas de Informação, Comunicação e Ciência da Informação." (MOLINA; VALENTIM, 2011, p. 267). Na Ciência da Informação estudos voltados para essa temática têm crescido e isso ocorre porque o seu objeto de estudo, a informação, está estritamente correlacionada com a memória.

Conforme explica Jardim (1995, p. 1) a memória é “[...] expressão de interesses e paixões e objeto de um campo interdisciplinar. Diversos termos tendem a ser associados à memória: resgate, preservação, conservação, registro, seleção etc.”. É notório que a memória, enquanto processo, contribui significativamente com a preservação da informação, do conhecimento, de histórias vividas e narradas que podem ser ressignificadas no presente "com imagens e ideias de hoje, experiências do passado" (BOSI, 1994, p. 55).

De acordo com Pollak (1992), a memória é marcada por acontecimentos vividos tanto pessoalmente, quanto individualmente, e até mesmo em grupos, 
nos quais o sujeito sente pertencente, trazendo a ideia da identidade. A memória individual e a memória coletiva contribuem significativamente com o processo de construção da Memória Institucional, assim como também da Memória Organizacional. Isto porque tanto uma instituição quanto uma organização, que é formada por um indivíduo ou por grupos de pessoas, possuem memória. Em sua pesquisa de dissertação, Loureiro (2016) explica que,

No caso específico das instituições, nos parece possível compreender que a memória pode ser recuperada e reutilizada de diversas maneiras, de modo a atender dado apelo do presente pela recuperação desta memória ou aprendizado passado. Assim, garantir o registro das memórias individuais e coletivas ao longo da vida institucional pode ser de extrema valia para usos que não são totalmente passíveis de serem previstos. (LOUREIRO, 2016, p. 74).

Para Crippa (2010), “A noção de memória, tanto individual como coletiva, tende a se identificar com uma visão estritamente tecnológica, tornando comum o hábito de considerar que todo conhecimento necessário está registrado em algum suporte externo.” (CRIPPA, 2010, p. 105). Neste cenário, a Memória Organizacional está direcionada pela preservação dos conhecimentos adquiridos e gerados durante toda a vida organizacional para responder às questões presentes nas atividades das organizações, bem como contribuir na tomada de decisão acertada, relacionando-se diretamente com os processos de Gestão do Conhecimento (GC) nas organizações.

A “GC consiste na integração de processos simultâneos, desde a criação ao uso pleno do conhecimento [...] no ambiente das organizações." (DUARTE, 2003, p. 283). Assim, a principal função de uma Memória Organizacional é aumentar a competitividade da organização, pelo aperfeiçoamento da forma como ela gerencia seu conhecimento (ABECKER et al., 1998).

Quanto às definições e/ou conceitos de Memória Organizacional, Walsh e Ungson (1991) definem-na como informações que estão armazenadas e relacionadas à história de uma organização que podem ser utilizadas nos processos de tomada de decisão e podem estar retidas em seis lugares: indivíduos, cultura organizacional, transformações organizacionais, estruturas organizacionais, ecologia organizacional e arquivos externos. 
Abecker e outros (1998) defendem que a Memória Organizacional é uma ferramenta que, além de ser um repositório de informação, também possibilita à organização o compartilhamento e reuso do conhecimento corporativo, individual e de aprendizagem das rotinas diárias da organização. Nessa perspectiva, a memória das organizações amplia, captura, organiza, divulga e reutiliza o conhecimento dos funcionários gerado no dia a dia da organização (CONKLIN, 2001).

Compreendemos que a $\mathrm{MO}$ vai além da preservação dos acontecimentos passados, das experiências vividas e da história da organização, sendo compreendida como uma ferramenta que possibilita a melhoria das atividades administrativas no tempo presente, a partir do Conhecimento Organizacional criado em tempos passados. Assim, Menezes (2006, p. 31) define como

[...] acervo de informação, conhecimentos e práticas, agregados e retidos pela organização ao longo de sua existência, utilizados para o suporte às suas atividades, seus processos decisórios e para a preservação do seu capital intelectual, potencializando a gestão do conhecimento.

É possível, então, inferir que a funcionalidade da Memória Organizacional torna-se muito importante para o aumento da vantagem competitiva das organizações e melhoria de posicionamento estratégico no mercado, no qual se valoriza cada vez mais o conhecimento. Portanto, compreendendo a memória e suas contextualizações no âmbito organizacional, apresentamos as possíveis relações entre a $\mathrm{MO}$ e o conhecimento das organizações.

\section{Memória Organizacional e Conhecimento Organizacional: tecendo relações}

Com o avanço tecnológico, político e econômico, crescem nas organizações as buscas por outras estratégias para adequar-se às mudanças exigidas por novas realidades. Assim, é preciso não deixar de acompanhar a valorização da Memória Organizacional e sua relação com o Conhecimento Organizacional, 
quando, cada vez mais configuram-se como uma forma de alavancar a eficácia organizacional. Não se pode negar a sua importância para a gestão, fato que exige um envolvimento de todos, fomentando uma cultura organizacional diante dos desafios contemporâneos.

Nesse viés, o conhecimento e a memória podem assumir novas perspectivas, constituindo-se como um importante diferencial, já que a memória organizacional pode ser entendida como a habilidade das organizações para salvar, reter e fazer uso de informações do passado nas atividades atuais, enquanto que o conhecimento, quando compartilhado, pode ampliar as possibilidades de crescimento das organizações.

Choo (2006, p. 179) aborda o conhecimento como “[...] um elemento estratégico, essencial e que se configura como uma propriedade de vantagem competitiva e duradoura para uma organização.”. Nas organizações e em nossa sociedade, de maneira geral, o conhecimento está presente desde tempos remotos. Esse conhecimento passa a ser considerado como uma fonte necessária em um ambiente de incertezas, e suas formas de compartilhamento podem ser instrumentos para contribuir com o seu processo de gestão.

A gênese da relação da memória e do conhecimento organizacional está identificada na interação de duas perspectivas através da integração das duas formas de conhecimento: tácito e explícito. Assim, de acordo com Nonaka e Takeuchi (2007), o conhecimento pode estar tanto presente nas pessoas (conhecimento tácito) como embutido em produtos, processos, serviços, ferramentas ou ainda registrado em documentos (conhecimento explícito), construindo a Memória Organizacional, como ocorre nas comunidades de prática quando o conhecimento é compartilhado.

De acordo com Araújo (2014), “A contribuição das noções de tácito e explícito de Polanyi foi fundamental para o avanço desta área." (ARAÚJO, 2014, p. 64). Passaram-se os anos e autores como Nonaka e Takeuchi (2008, p.182) ainda afirmam que "[...] o conhecimento tácito dos indivíduos constitui a base da criação do conhecimento organizacional. A organização tem de mobilizar o conhecimento tácito criado e acumulado no nível individual.”, 
gerando assim, possibilidades de compartilhamento e de estruturação da Memória Organizacional.

Nesse cenário, faz-se necessário compreender que a memória e o conhecimento organizacional vêm se transformando em recursos que, cada vez mais, agregam valor de qualidade, pois o seu domínio por toda organização pode ser um fator importante para o seu crescimento. Desta maneira, desenvolver estratégias para a estruturação de uma memória para organização do Conhecimento Organizacional é um desafio, porque não se trata de um repasse de informações que visa ao aprendizado de novos conhecimentos, habilidades ou destrezas com o objetivo de que elas se tornem mais eficientes e eficazes.

Partindo dessas premissas, Choo (2006) afirma que toda mudança que envolve pessoas produz contradições no ambiente organizacional, e que, para minimizá-las, é preciso gerar informações claras e confiáveis e estabelecer espaços participativos à discussão do processo, além de espaços permanentes para as trocas de experiências e de avaliação. Assim, tanto a Memória Organizacional como o conhecimento trilham uma relação de criação e armazenamento para organização, permitindo a recuperação, acesso e uso posterior.

Um grande desafio para as organizações que desejam se tornar criadoras do conhecimento e aproveitá-lo estrategicamente está na adoção de práticas que sejam compatíveis com as mudanças necessárias, mesmo diante das ambiguidades, conflitos do ambiente e da interdependência dos conhecimentos tácitos para um conhecimento explícito ou vice-versa, promovendo inovações e desenvolvimento de novos produtos e serviços.

Considerando então que o conhecimento é um recurso que pode ser obtido por meio das pessoas e das suas ações, experiências, emoções e valores ideais do indivíduo, as práticas de compartilhamento de conhecimento estarão sempre relacionadas à memória organizacional. No momento, apresentamos a pesquisa realizada na BRAPCI, no intuito de entendermos os conceitos sobre Memória Organizacional a partir dos trabalhos recuperados, identificando suas relações com o Conhecimento Organizacional. 


\section{Procedimentos metodológicos}

$\mathrm{O}$ artigo configura-se por meio da pesquisa documental do tipo exploratória. Quanto ao seu objetivo, é descritivo com abordagem qualiquantitativa, uma vez que visa a quantificar e descrever os conceitos de Memória Organizacional por meio das produções indexadas na BRAPCI, tendo como corpus de análise os artigos científicos.

A preferência por estudar a BRAPCI justifica-se por ela ser uma das bases mais acessadas e por ser amplamente reconhecida pelos pesquisadores da área. A BRAPCI é produto de um projeto financiado pelo Conselho Nacional de Desenvolvimento Científico e Tecnológico (CNPq), possuindo um acervo de publicações brasileiras em Ciência da Informação. Atualmente, disponibiliza referências e resumos de 19.255 textos publicados em 57 periódicos nacionais, impressos e eletrônicos, da área de Ciência da Informação com trabalhos a partir de 1972.

O corpus de análise concentrou-se nas produções que apresentavam como foco de abordagem a Memória Organizacional, com a finalidade de identificar os conceitos apresentados nos artigos relacionados ao Conhecimento Organizacional. Assim, não foi objetivo da pesquisa comparar os conceitos de Memória Organizacional com os de Conhecimento Organizacional, tendo em vista que o objetivo central do artigo foi analisar as possíveis relações entre as temáticas exclusivamente nas produções sobre MO, o que justifica a busca de artigos que se referem à MO na base de dados pesquisada.

Para identificar os conceitos de MO na $\mathrm{CI}$, foram realizadas as buscas dos termos "memória organizacional" e "organizational memory", separadamente, desde o início da indexação de artigos de periódicos na BRAPCI até o final do ano de 2017. Como resultado de busca, recuperou-se um total de 19 artigos que atendiam ao objetivo de análise temática, conforme evidenciado no Quadro 1.

Quadro 1 - Referências dos artigos recuperados processo nas pactuações da comissão intergestores bipartite do sistema único de saúde. Encontros Bibli: Revista Eletrônica de Biblioteconomia e Ciência da Informação, Florianópolis, v. 14, n.27, 2009. 
SASIETA, H. A. M.; MEPPLER, F. D.; PACHECO, R. C. A memória organizacional no contexto da engenharia do conhecimento. DataGramaZero - Revista de Informação, Rio de Janeiro, v. 12 n.3 ago/2011.

SANTOS, A. P. Amnésia Organizacional: um Estudo de Caso Sobre a Memória na Administração Pública Federal. InCID: Revista de Ciência da Informação e Documentação, Ribeirão Preto, v. 3, n.1, p. 36-56, jan./jun. 2012.

DRUZIANI, C. F. M.; CATAPAN, A. H. A percepção da memória organizacional no setor público de tecnologia da informação. Perspectivas em Gestão \& Conhecimento, João Pessoa, v. 2, n. 2, p. 97-121, jul./dez. 2012.

ZANCANARO, A. et al. Mapeamento da produção científica sobre memória organizacional e ontologias. Perspectivas em Ciência da Informação, Belo Horizonte, v.18, n.1, p.43-65, jan./mar. 2013.

ESTEVÃO, J. S. B.; STRAUHS, F. R. Proposta de uma ontologia como modelo de referência no domínio da Memória Organizacional Histórica. Perspectivas em Ciência da Informação, Belo Horizonte, v.18, n.4, p.35-53, out./dez. 2013.

MOLINA, L. G.; VALENTIM, M. L. P. Memória organizacional: proposta de um modelo para implantação em instituições. RICI: Revista Ibero-Americana de Ciência da Informação, Brasília, v. 7, n. 2, p. 45-64, ago./dez. 2014.

MOLINA, L. G.; VALENTIM, M. L. P. Memória organizacional como forma de preservação do conhecimento. Perspectivas em Gestão \& Conhecimento, João Pessoa, v. 5, n. 2, p. 147 169, jul./dez. 2015.

ANDRELO, R.; BIGHETTI, W. V. F. A internet como instrumento da democracia: um estudo comparativo entre as memórias virtuais dos parlamentos do Reino Unido e do Brasil. Liinc em Revista, Rio de Janeiro, v.11, n.1, p. 52-68, mai/2015.

PEREIRA, M. F. et al. Memória organizacional e as suas contribuições para o Fundo Setorial - CT-INFRA-UFPR. Perspectivas em Gestão \& Conhecimento, João Pessoa, v. 6, n. 1, p. 128-140, jan./jun. 2016.

SCHWEITZER, F.; RADOS, G. V. Informação, conhecimento e memória organizacional: mapeamento da produção científica. Revista ACB: Biblioteconomia em Santa Catarina, Florianópolis, v. 21, n. 1, p. 137-144, dez./mar., 2016.

SANTARÉM, V. PAZIN VITORIANO, M. C. C. P. Gestão da informação, fluxos informacionais e memória organizacional como elementos da inteligência competitiva. Perspectivas em Gestão \& Conhecimento, João Pessoa, v.5, Número Especial, p.158-170, jan. 2016.

NASCIMENTO, N. M. et al. Gerenciamento dos fluxos de informação como requisito para a preservação da Memória organizacional: um diferencial competitivo. Perspectivas em Gestão \& Conhecimento, João Pessoa, v. 6, Número Especial, p. 29-44, jan. 2016.

COSTA, A. S. M.; SILVA, M. A. C. Empresas, ditadura civil militar brasileira e centros de Memória e documentação corporativos: um estudo exploratório. LOGEION: Filosofia da informação, Rio de Janeiro, v. 2, n. 1, p.122-144, set. 2015/fev. 2016.

OTTONICAR, S. L. C.; CONDUTA, L. F.; PAZIN VITORIANO, M. C. C. P. Competência em Informação e Cultura Organizacional: fatores fundamentais na construção da memória organizacional. InCID: Revista de Ciência da Informação e Documentação, Ribeirão Preto, v. 7, n. 1, p. 111-130, mar./ago. 2016.

FREITAS JÚNIOR, O. G. et al. Uma arquitetura para sistemas de gestão do Conhecimento orientada a grupos de pesquisa e desenvolvimento. Perspectivas em Gestão \& Conhecimento, João Pessoa, v. 7, Número Especial, p. 126-144, mar. 2017.

CAÑAVATE, A. M. et al. Os arquivos empresariais em Portugal: do tradicional ao cloud computing. Perspectivas em Ciência da Informação, v.22, n.3, p.210-251, jul./set. 2017.

NASCIMENTO, N. M.; PAZIN VITORIANO, M. C. C. P. O estudo da produção documental e a memória organizacional em ambientes empresariais. Em Questão, Porto Alegre, v. 23, n. 1, p. 202-227, jan/abr. 2017.

FEITOZA, R. A. B.; DUARTE, E. N. A interface entre a memória organizacional e a gestão do conhecimento. ÁGORA, Florianópolis, v. 27, n. 55, p. 401-428, jul./dez., 2017. 
Para a organização e análise dos dados, foi adotada a análise de conteúdo enquanto método de procedimento, seguindo a técnica de análise temática, proposta por Bardin (2011). De acordo com a autora, a análise temática “[...] consiste em descobrir os 'núcleos de sentido' que compõem a comunicação e cuja presença ou frequência de aparição podem significar alguma coisa para o objetivo analítico estudado.”. (BARDIN, 2011, p. 135). Portanto, com o objetivo de analisar os conceitos sobre a temática Memória Organizacional e conhecer suas possíveis relações com o Conhecimento Organizacional, definiram-se, enquanto unidades da amostragem, os artigos publicados na BRAPCI que apresentassem como abordagem central a temática supracitada.

$\mathrm{Na}$ fase de pré-análise, a leitura do material pesquisado na base de dados viabilizou o mapeamento das obras que abordavam o assunto, permitindo assim a escolha dos documentos a serem analisados seguindo a concepção de Bardin (2011, p. 135) de que o "[...] tema é a unidade de significação que se liberta naturalmente de um texto analisado segundo critérios relativos à teoria que serve de guia à leitura.”.

Durante a exploração do material, os dados foram coletados e organizados em quadros, nuvem de representação e gráficos para uma compreensão geral do assunto estudado, até chegarmos à fase de identificação dos conceitos abordados pelos teóricos citados no corpo dos artigos científicos. Assim, finalizamos com a fase do tratamento dos resultados, por meio das inferências e interpretações baseadas na revisão de literatura realizada para pesquisa.

\section{Mapeamento e análise da produção científica em Memória Organizacional na BRAPCI}

Estudos que visam a caracterizar produções científicas possibilitam o monitoramento e avaliação de temáticas e suas relações com áreas associadas, assim como a construção de perfis comportamentais de pesquisadores, o que vem contribuindo para o avanço de pesquisas dessa natureza em diferentes áreas. Sabe-se que a análise da produção científica sobre determinado tema é 
sensível às particularidades e características de cada área, sendo necessário, além de um levantamento quantitativo, análises qualitativas que ofereçam subsídios suficientes para o entendimento do estudo em questão.

Pensando nisso, desenvolveu-se a presente pesquisa, que mapeou a produção científica sobre Memória Organizacional publicada na BRAPCI para alcançarmos o objetivo do estudo por meio da análise conceitual abordada nos artigos recuperados, fazendo uso da técnica de análise temática (BARDIN, 2011).

Para organização dos dados, foram criadas cinco categorias: autores que mais se destacaram pela quantidade de trabalhos sobre a temática na base, distribuição de artigos de periódicos sobre MO por ano, periódicos indexados na BRAPCI que mais publicaram sobre o tema, principais palavras-chave abordadas pelos trabalhos analisados e, por último, a análise dos conceitos sobre Memória Organizacional para o entendimento de suas relações com Conhecimento Organizacional.

\subsection{Autores mais produtivos sobre MO na BRAPCI}

Foram identificadas um total de 46 autorias dos trabalhos recuperados, classificados em autores e coautores. Entre eles destacaram-se cinco, por possuírem dois ou três pesquisas sobre MO na base, superando os demais pesquisadores que tiveram uma publicação conforme representa o Gráfico 1 abaixo:

Gráfico 1 - Autores mais produtivos sobre MO na BRAPCI

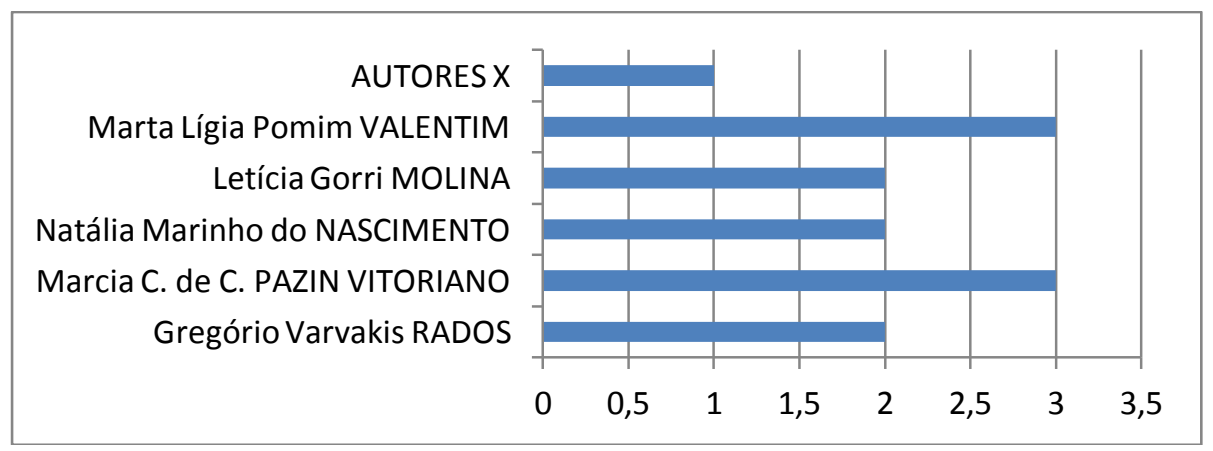

Fonte: Dados da pesquisa.

Nota: Autores X (possuem apenas um trabalho na base, distribuídos como autores ou coautores). 
Podemos observar que a autora Marta Lígia Pomim Valentim possui três trabalhos sobre MO indexados na BRAPCI, sendo como coautoria nos respectivos trabalhos: Memória organizacional: proposta de um modelo para implantação em instituições e Memória organizacional como forma de preservação do conhecimento, correspondentes à autoria de Letícia Gorri Molina e Gerenciamento dos fluxos de informação como requisito para a preservação da Memória organizacional: um diferencial competitivo que tem como autoria Natália Marinho do Nascimento.

Nascimento também é autora em $O$ estudo da produção documental e a memória organizacional em ambientes empresariais, em parceria com Márcia C. de C. Pazin Vitoriano. Esta, representada também pelos artigos Gestão da informação, fluxos informacionais e memória organizacional como elementos da inteligência competitiva e em Competência em Informação e Cultura Organizacional: fatores fundamentais na construção da memória organizacional.

O autor Gregório Jean Varvakis Rados possui coautoria em dois trabalhos intitulados A construção da memória organizacional utilizando o gerenciamento de processo nas pactuações da comissão intergestores bipartite do sistema único de saúde e Informação, conhecimento e memória organizacional: mapeamento da produção científica.

\subsection{Trabalhos recuperados na BRAPCI}

A partir do levantamento dos artigos publicados na BRAPCI, de forma abrangente, foi possível identificar um total de 19 artigos distribuídos entre o período de 2009 a 2017, relacionados ao tema Memória Organizacional. A maior concentração ocorre em 2016, com seis artigos, e em 2017 com quatro artigos abordando os temas. O Gráfico 2 apresenta, quantitativamente, esses resultados por ano de publicação. 
Gráfico 2 - Evolução de trabalhos indexados na BRAPCI sobre MO

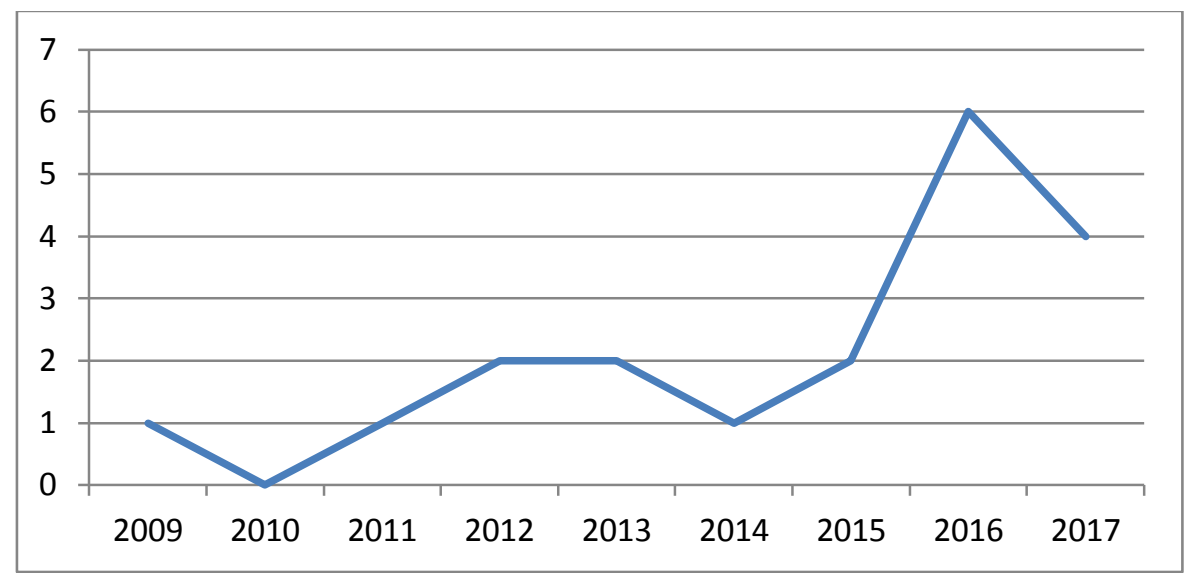

Fonte: Dados da pesquisa.

O Gráfico 2 evidencia um crescimento no número de publicações nas edições desde 2009, com exceção em 2010, quando não houve publicação sobre a temática, e com apenas uma incidência até a edição de 2016, que apresentou seis artigos publicados sobre o assunto. Em 2017, o número caiu para quatro publicações, saindo do padrão crescente visto durante os últimos oito anos. De todo modo, os dados representam um aumento no interesse, por parte dos pesquisadores, em estudar a estrutura organizacional das empresas, evidenciando a necessidade de expandir as pesquisas envolvendo a cultura e memória das organizações. Esse dado tem relação com o fato das temáticas como Memória Organizacional e Gestão do Conhecimento terem crescido em importância para pesquisadores e organizações, ao longo dos anos 2000 (SANTOS , J.; URIONA-MALDONADO; SANTOS, R., 2011).

Com o crescimento acelerado do volume de conteúdo informacional na sociedade contemporânea, as pequenas e médias empresas passaram a buscar e desenvolver mecanismos tecnológicos para o gerenciamento e preservação dos dados e informações, com vistas no acesso e uso. Essa procura acompanha o desenvolvimento das Tecnologias Digitais de Informação e Comunicação (TDIC), que, nos últimos anos, têm se desenvolvido cada vez mais e de modo rápido.

Por esse motivo, muitos estudos de caso passaram a ser desenvolvidos visando a desenvolver estratégias para estruturar a memória das organizações, quase sempre tão ubíqua e efêmera, gerando conhecimento. Isso foi evidenciado 
no Quadro 1, qual destacamos a incidência de artigos que apresentam modelos de Memória Organizacional como produto das pesquisas.

\subsection{Periódicos indexados na BRAPCI com artigos sobre Memória Organizacional}

Os periódicos que compuseram o corpus de estudo foram contabilizados e apresentados por ordem de maior produtividade. A distribuição dos títulos dos periódicos configura-se desta maneira:

Gráfico 3 - Periódicos indexados na BRAPCI com artigos sobre MO

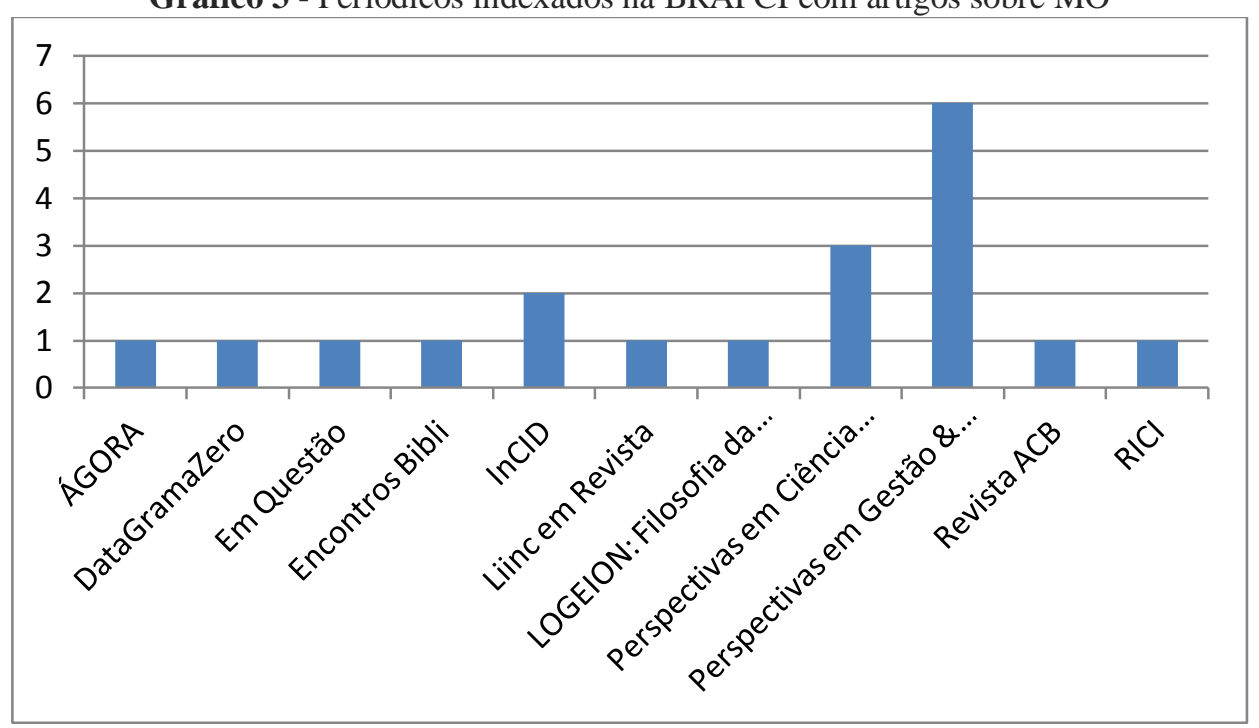

Fonte: Dados da pesquisa.

O Gráfico 3 permite verificar que os 19 trabalhos recuperados na base de dados BRAPCI estão distribuídos entre 10 periódicos distintos da área de Ciência da Informação e um na área de Filosofia, os quais se encontram indexados nesta base. Em relação à frequência de títulos por periódicos, verifica-se que a revista Perspectivas em Gestão \& Conhecimento $(P G \& C)$ é a que possui maior número de artigos publicados, com um total de seis artigos. Este dado pode ser justificado pelo escopo da revista, que tem como objetivo principal publicar artigos relacionados às temáticas Gestão e Conhecimento sob abordagens inter/pluri/multi/transdisciplinares. Nesse sentido, a revista apresenta como foco de estudo as grandes áreas que englobam a Gestão, a 
Memória, o Usuário e o Conhecimento nas Organizações - a partir da perspectiva da CI.

Em relação ao ano de publicação, verificamos que seis artigos da revista $P G \& C$ foram publicados na mesma edição de 2016. Esse fato está relacionado à uma publicação de número especial, denominada Inteligência Organizacional e Gestão do Conhecimento, assuntos que se relacionam diretamente com à temática estudada.

\subsection{Incidência de palavras-chave nos artigos sobre Memória Organizacional}

Os trabalhos analisados utilizaram 81 palavras-chave em sua totalidade; dentre as principais, destacam-se: Memória Organizacional; Gestão do Conhecimento; Informação; Administração; Memória; Ontologias; Arquivo; Reutilização da Informação; Cultura informacional; Fluxos informacionais e Arquivos empresariais, conforme Figura 1.

Figura 1 - Nuvem de representação das palavras-chave utilizadas nos artigos recuperados

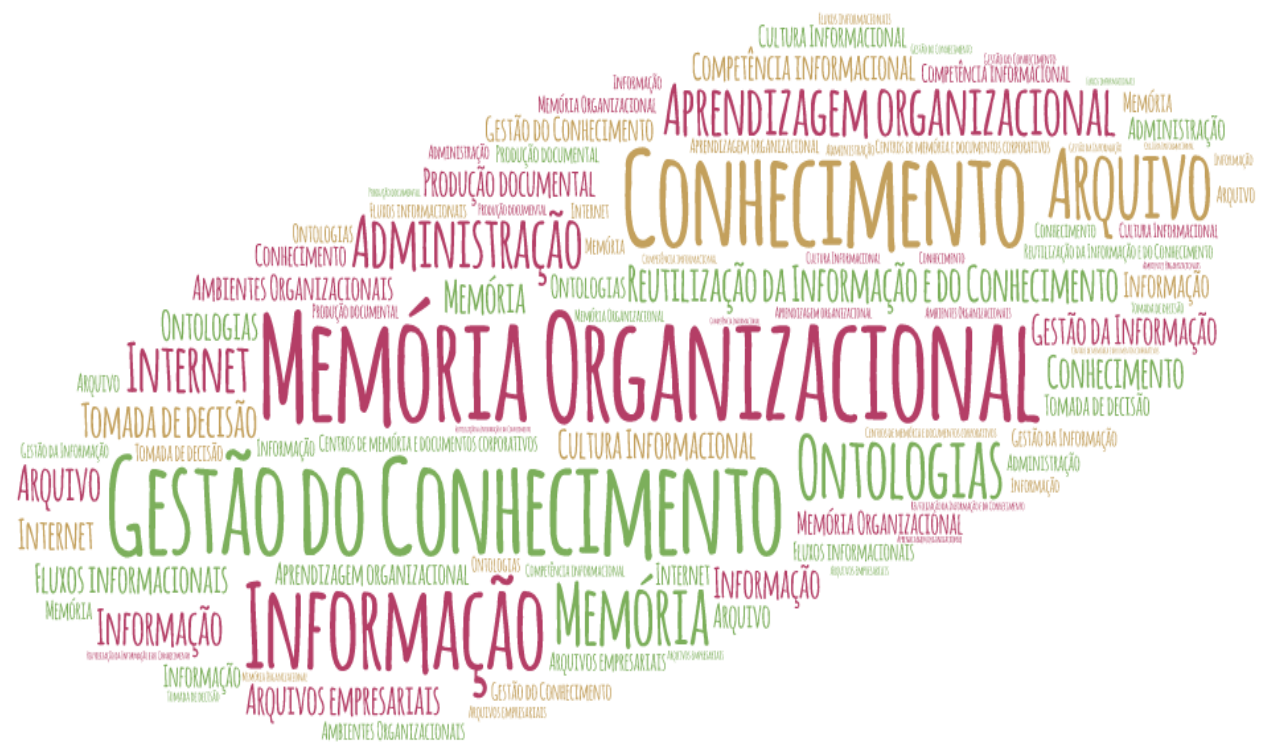

Fonte: Dados da pesquisa.

Podemos observar que o termo "Memória Organizacional" apresenta um grau de maior centralidade e destaque por ser o tema dos trabalhos analisados, tendo uma ocorrência considerável. "Gestão do Conhecimento" aparece 
consideravelmente nos artigos apresentados, ratificando seu diálogo, entre os aspectos teóricos e práticos, com a memória nos ambientes empresariais. Assim, percebemos que a GC dialoga com a MO.

A Figura 1 permite-nos inferir que os trabalhos possuem variedades de terminologias, que se caracterizam pelas temáticas as quais caminham juntamente com a memória organizacional, seja nos seus aspectos teóricos ou nos práticos. O descritor - Administração - é visível e remete à ideia de que os temas trabalhados no campo da CI, como a MO, são interdisciplinares (SARACEVIC, 1996) nas pesquisas estudadas.

Os descritores "centro de memória e documentação", "documentos empresarias", "produção documental" e "arquivos" são palavras-chave que nos permitem considerar a relação entre a Memória Organizacional e os documentos arquivísticos, bem como os arquivos das organizações. Por meio dessas palavras-chave, inferimos que parte dos trabalhos analisados mencionam os arquivos como aproximação ao conceito de $\mathrm{MO}$, o que ratifica a ideia de Walsh e Ungson (1991) ao abordarem os seis lugares de retenção do conhecimento nas organizações, sendo eles: os indivíduos, a cultura organizacional, as transformações organizacionais, as estruturas organizacionais, a ecologia organizacional e os arquivos externos.

Os descritores que aproximam a MO da subárea Gestão da Informação e do Conhecimento da Ciência da Informação, são: cultura informacional, fluxos informacionais, competência informacional, ambientes empresariais, conhecimento e tomada de decisão, entre outros.

\subsection{Relação da Memória Organizacional com o Conhecimento Organizacional}

Para identificar a relação da MO com o Conhecimento Organizacional, destacamos os conceitos mais recorrentes encontrados nos artigos que compõem o corpus da pesquisa. Assim, é por meio deles que podemos observar como a memória das organizações está associada ao conhecimento organizacional, 
considerando que a $\mathrm{MO}$ possibilita a promoção da GC no âmbito das organizações.

O Quadro 2 apresenta os autores responsáveis por cada conceito

explicitado, bem como o ano correspondente a cada trabalho, a seguir:

Quadro 2 - Autores e conceitos identificados nos artigos pesquisados na BRAPCI

\begin{tabular}{|c|c|}
\hline Autor (es) e ano & Conceito \\
\hline $\begin{array}{l}\text { Walsh;Ungson } \\
\text { (1991, grifo nosso) }\end{array}$ & $\begin{array}{l}\text { Definem que Memória Organizacional se refere a informações } \\
\text { armazenadas a partir da história de uma organização que pode ser } \\
\text { exercida sobre as decisões presentes. Essa informação é armazenada } \\
\text { em consequência da execução das decisões a que se referem, por } \\
\text { lembranças individuais e através de interpretações } \\
\text { compartilhadas, podendo estar retida em seis lugares: indivíduos, } \\
\text { cultura organizacional, transformações organizacionais, estruturas } \\
\text { organizacionais, ecologia organizacional e arquivos externos. }\end{array}$ \\
\hline $\begin{array}{c}\text { Stein } \\
(1995, \text { grifo nosso) }\end{array}$ & $\begin{array}{l}\text { Compartilhamento do conhecimento [...] para usá-lo nas atividades } \\
\text { atuais, melhorando assim a eficácia organizacional. }\end{array}$ \\
\hline $\begin{array}{c}\text { Conklin } \\
\text { (1997, grifo nosso) }\end{array}$ & $\begin{array}{l}\text { A Memória Organizacional está voltada para estender e amplificar } \\
\text { o conhecimento pela captura, organização, disseminação e reuso por } \\
\text { colaboradores de uma determinada organização. }\end{array}$ \\
\hline $\begin{array}{c}\text { Abecker } \\
(1998, \text { grifo nosso) }\end{array}$ & $\begin{array}{l}\text { Memória Organizacional [...] tem papel de gerenciador dos ativos } \\
\text { intelectuais da organização. Essa gestão abrange desde a } \\
\text { identificação do conhecimento necessário, organização, } \\
\text { preservação e, finalmente, divulgação e uso. }\end{array}$ \\
\hline $\begin{array}{c}\text { Lehner e Maier } \\
(2000, \text { grifo nosso) }\end{array}$ & $\begin{array}{l}\text { MO é um sistema capaz de armazenar as coisas percebidas, } \\
\text { experimentadas ou vividas para além da duração da ocorrência } \\
\text { atual, e permitir recuperá-las posteriormente. }\end{array}$ \\
\hline $\begin{array}{l}\text { Conklin }{ }^{1}(1996 \text { apud } \\
\text { CERANTE; } \\
\text { SANTOS, 2000, } \\
\text { p.109, grifo nosso) }\end{array}$ & $\begin{array}{l}\text { "A habilidade que as empresas devem possuir é a de manipular, } \\
\text { distribuir e integrar esta informação e inteligência armazenadas } \\
\text { de forma eficiente e contínua dando origem a uma memória } \\
\text { organizacional.". }\end{array}$ \\
\hline $\begin{array}{l}\text { Atwood } \\
(2002, \text { grifo nosso) }\end{array}$ & $\begin{array}{l}\text { Nas comunidades de prática a memória organizacional é uma } \\
\text { combinação de experiências e conhecimentos sobre projetos, } \\
\text { produtos e decisões que estão frequentemente incorporados nas } \\
\text { mentes dos trabalhadores ou na cultura da organização como } \\
\text { conhecimento tácito. }\end{array}$ \\
\hline $\begin{array}{l}\text { Hatami; Galliers; } \\
\text { Huang } \\
\text { (2003, grifo nosso) }\end{array}$ & $\begin{array}{l}\text { Memória organizacional é um instrumento de retenção do } \\
\text { conhecimento organizacional que possibilita armazenar o } \\
\text { conhecimento tácito explicitado das mentes humanas, bem como } \\
\text { também contribuir para o aprendizado por meio de experiências } \\
\text { passadas e sustenta os processos decisórios. }\end{array}$ \\
\hline $\begin{array}{c}\text { Macedo } \\
(2003, \text { grifo nosso) }\end{array}$ & $\begin{array}{l}{[\ldots] \text { o conhecimento que é produzido e organizado }} \\
\text { institucionalmente se constitui em uma base de conhecimentos } \\
\text { fundamental para a tomada de decisão no ambiente organizacional e, } \\
\text { que por sua vez, se traduzem em ações estratégicas, financeiras e } \\
\text { administrativas, essas bases de conhecimento denominamos de MO. }\end{array}$ \\
\hline $\begin{array}{l}\text { Yagui } \\
(2003, \text { p. } 71-72, \text { grifo } \\
\text { nosso) }\end{array}$ & $\begin{array}{l}\text { "A MO pode ser considerada um instrumento de apoio } \\
\text { organizacional, visto que objetiva a preservação da memória técnica, } \\
\text { gerencial e de negócios, além de constituir-se em uma fonte de } \\
\text { aprendizado organizacional com valor agregado, e possibilita } \\
\text { gerar diferenciais competitivos frente ao ambiente de negócios no } \\
\text { qual a empresa está inserida.". }\end{array}$ \\
\hline Damante & "A MO [...] além de seu acervo documental institucional, como \\
\hline
\end{tabular}




\begin{tabular}{|c|c|}
\hline $\begin{array}{l}\text { (2004, p. } 40, \text { grifo } \\
\text { nosso) }\end{array}$ & $\begin{array}{l}\text { "objetos, embalagens, fotos, campanhas, documentos e registros com } \\
\text { valor de guarda permanente' precisa, efetivamente, servir de } \\
\text { fomento à Gestão do Conhecimento.". }\end{array}$ \\
\hline $\begin{array}{l}\text { Bellotto } \\
(2004, \text { p. } 271)\end{array}$ & $\begin{array}{l}\text { "Defende que a memória organizacional é algo que vai muito além } \\
\text { do próprio conteúdo do documento. Os conjuntos informacionais que } \\
\text { se geram não podem ser definidos compartimentadamente como } \\
\text { material de arquivo, de biblioteca ou de centro de documentação, por } \\
\text { serem atípicos, como totalidade, a qualquer um deles. Esses } \\
\text { conjuntos de dados constituem a memória." }\end{array}$ \\
\hline $\begin{array}{l}\text { Huber }^{2}(1991) ; \text { Walsh } \\
\text { e Ungson }{ }^{3}(1991) \\
\text { citado por Ke e Wei } \\
\text { (2006, p. 3, grifo } \\
\text { nosso) }\end{array}$ & $\begin{array}{l}\text { "Memória organizacional resulta do conhecimento das } \\
\text { organizações armazenado para o uso futuro.". }\end{array}$ \\
\hline $\begin{array}{l}\mathrm{O}^{\prime} \text { Toole }^{4} \text { (1999 apud } \\
\text { Almeida, 2006, p. } 87 \\
\text { grifo nosso) }\end{array}$ & $\begin{array}{l}\text { "A memória organizacional diz respeito a "como" e a "de que" as } \\
\text { organizações se lembram: dados, informações e conhecimento são } \\
\text { retidos pela organização [...], e podem ser acessados por vários } \\
\text { indivíduos ou grupos de indivíduos.". }\end{array}$ \\
\hline $\begin{array}{l}\text { Rao e Argote } \\
\text { (2006, grifo nosso) }\end{array}$ & $\begin{array}{l}\text { A memória da organização é o conteúdo distribuído em vários } \\
\text { reservatórios, repositórios ou caixas de retenção. Os conhecimentos } \\
\text { retidos pelos indivíduos interagem com o conhecimento embutido } \\
\text { em papéis e rotinas. }\end{array}$ \\
\hline $\begin{array}{l}\text { Almeida } \\
\text { (2006, grifo nosso) }\end{array}$ & $\begin{array}{l}\text { Memória organizacional é, portanto, um conceito metafórico, que } \\
\text { pressupõe a capacidade das organizações de lembrar de forma } \\
\text { semelhante ao homem e indica a necessidade de identificar } \\
\text { mecanismos capazes de gerar conhecimento e retê-lo. }\end{array}$ \\
\hline $\begin{array}{l}\text { Menezes } \\
(2006, \text { p. } 32 \text {, grifo } \\
\text { nosso) }\end{array}$ & $\begin{array}{l}\text { A MO "[...] é considerada um instrumento de retenção do } \\
\text { conhecimento organizacional, que não só possibilita reter parte do } \\
\text { conhecimento tácito explicitado pelos sujeitos organizacionais, bem } \\
\text { como propicia o aprendizado por meio das experiências passadas } \\
\text { alicerçando o processo decisório". Ou, "[...] acervo de informação, } \\
\text { conhecimento e práticas, agregados e retidos pela organização ao } \\
\text { longo de sua existência, utilizados para o suporte às suas atividades, } \\
\text { seus processos decisórios e para a preservação de seu capital } \\
\text { intelectual, potencializando a gestão do conhecimento.". }\end{array}$ \\
\hline $\begin{array}{c}\text { Moresi } \\
(2006, \text { p. } 289, \text { grifo } \\
\text { nosso) }\end{array}$ & $\begin{array}{l}\text { "Memória Organizacional é normalmente definida em termos dos } \\
\text { conteúdos e dos processos associados à memória de uma } \\
\text { organização." }\end{array}$ \\
\hline $\begin{array}{c}\text { Jackson } \\
\text { (2007, grifo nosso) }\end{array}$ & $\begin{array}{l}\text { É o conhecimento de como fazer as coisas, a forma de abordar os } \\
\text { problemas e questões, como tratamos uns aos outros. }\end{array}$ \\
\hline $\begin{array}{l}\text { Spiller e Pontes } \\
(2007, \text { p. } 99 \text {, grifo } \\
\text { nosso) }\end{array}$ & $\begin{array}{l}\text { "[...] as experiências pelas quais passa uma organização são } \\
\text { acumuladas ao longo dos anos, nas suas pessoas, cultura, processos e } \\
\text { em seus documentos, e esse conjunto de conhecimentos forma a sua } \\
\text { memória." }\end{array}$ \\
\hline $\begin{array}{c}\text { Nassar } \\
(2009, \text { grifo nosso) }\end{array}$ & $\begin{array}{l}\text { As formas de trabalhar a memória organizacional histórica vão do } \\
\text { resgate e restauração de documentos fundadores e arquivos } \\
\text { fotográficos até a estruturação de Centros de Memória e Referência, } \\
\text { nos quais a memória é trabalhada como conhecimento. }\end{array}$ \\
\hline $\begin{array}{c}\text { Fiedler; Welpe } \\
\text { (2010, grifo nosso) }\end{array}$ & $\begin{array}{l}\text { Conceitos de Memória Organizacional constituem uma estrutura de } \\
\text { repositórios, em que diferentes formas de conhecimentos são } \\
\text { armazenadas e podem ser recuperados. }\end{array}$ \\
\hline $\begin{array}{l}\text { Freire e outros } \\
\text { (2012, p. 44. grifo } \\
\text { nosso) }\end{array}$ & $\begin{array}{l}{[\ldots] \text { memória organizacional vai além do repositório, ela se }} \\
\text { configura numa estrutura de rede, tanto de pessoas, quanto de } \\
\text { artefatos, experiências e processos interligados, de modo a } \\
\text { configurar uma estrutura de conteúdos e conhecimentos preservados } \\
\text { ao longo do tempo de que se articulam de acordo com as } \\
\text { necessidades organizacionais em diferentes situações.". }\end{array}$ \\
\hline
\end{tabular}


Fonte: Dados da pesquisa.

Podemos observar que o conhecimento é um fenômeno presente nos conceitos expostos, e que funciona como elemento imprescindível para formação da Memória Organizacional. Dessa forma, a memória é composta por todo conhecimento produzido pelas ações dos colaboradores transformado em Conhecimento Organizacional.

O Quadro 2 apresenta uma síntese de diversas definições sobre MO, dentre elas, o trabalho de Walsh e Ungson (1991), o qual mostra que a informação e o conhecimento na pesquisa de Lehner e Maier (2000) (sobre as organizações enquanto algo valorado) agregam caráter inovador à tomada de decisão e aumentam a preocupação em preservar a sua memória para ter um conhecimento de maneira mais acertada.

Isso contribui para percepção da relação da MO com o Conhecimento Organizacional a partir dos objetivos que essa ferramenta pode oferecer. As obras se ascendem como referência para muitos autores da CI quando se trata de estudar e pesquisar a memória no contexto das organizações.

Almeida (2006) é um dos autores mais contemplados nos trabalhos analisados, conquistando espaço em grande parte do corpus desta pesquisa. Em sua tese, o autor conceitua a MO como algo metafórico, comparando-a com a memória individual - no sentido de obter e reter o conhecimento de maneira inteligente.

As definições de MO por Conklin (1997) e Abecker e outros (1998) podem ser caracterizadas como um ciclo do conhecimento gerado nas organizações, desde suas identificações ao seu uso pleno. Para esses autores, a memória das organizações é vista como um processo de criação, organização e acesso ao Conhecimento Organizacional, quando gerado, armazenado e preservado por meio desta memória.

Uma definição que aproxima muito a MO do Conhecimento Organizacional e, consequentemente, das práticas de Gestão do Conhecimento é proposta por Atwood (2002), ao trazer as comunidades de práticas como detentoras da memória das organizações, fazendo alusão ao conhecimento tácito, ou seja, o conhecimento que está na mente humana, sendo socializado por 
meio dessa estratégia de socialização do conhecimento e de combinações entre as experiências pessoais e as práticas exercidas na organização.

Spiller e Pontes (2007) caracterizam a Memória Organizacional como um conjunto de ações pessoais e institucionais que geram conhecimento e são acumuladas e preservadas ao longo do tempo, seja através das pessoas, da cultura, dos processos ou dos documentos - o que vai ao encontro de Moresi (2006), que defende de maneira mais ampla a MO por meio de conteúdos e processos.

Uma definição mais recente que pode ser observada é a de Freire et al. (2012), que, diferentemente de alguns autores citados, diz que MO vai além dos repositórios, sendo possível encontrá-la nas redes de troca de experiências e conhecimentos - tanto das pessoas como dos artefatos.

A partir da apresentação desses conceitos, podemos inferir que a Memória Organizacional tem, em suas bases conceituais, o propósito de garantir e resguardar o conhecimento criado durante a vida da organização. Nesse contexto, compreendemos que os processos de tomadas de decisão, as habilidades construídas e a socialização do conhecimento por meio das práticas de GC precisam ser registrados e armazenados nessa memória, que tem como objetivo preservar e disseminar o Conhecimento Organizacional.

Quando falamos em memória no contexto das organizações, estamos trabalhando diretamente com o conhecimento organizacional, pois todas as informações veiculadas, processadas e disseminadas nas rotinas de trabalho das organizações - pelas experiências individuais ou pelo conhecimento tácito dos colaboradores - passam a ser retidas pela organização.

Enfim, a MO interage com as atividades básicas de Gestão do Conhecimento, pois há inter-relações e convergências entre os processos de conhecimento, aprendizado e memória (ALMEIDA; PORTO, 2014). 


\section{Considerações finais}

A pesquisa desenvolvida em consonância com o objetivo deste trabalho possibilitou analisar os conceitos de MO, verificando suas relações dialógicas com o Conhecimento Organizacional e permitindo inferir que ambas as temáticas possuem correlações nos sentidos metodológicos, conceituais e práticos.

A MO pode ser entendida como uma área interdisciplinar que faz parte de outras áreas e constitui relações com diferentes campos de pesquisa, tais como: gestão do conhecimento, fluxos de informação, aprendizagem organizacional, cultura organizacional e engenharia do conhecimento.

A relevância de artigos dessa natureza é pertinente frente à importância de estabelecer perfis de estudo e abordagens teórico-práticas sobre temáticas interdisciplinares desenvolvidas no âmbito da Ciência da Informação. É preciso compreender o aporte teórico-conceitual não somente através de revisões de literatura, mas também por meio de revisões sistemáticas que possibilitem mapear e analisar a estrutura e dinâmica de assuntos abordados na área. Nesse sentido, salientamos a necessidade da ampliação de publicações visando à reflexão e discussões em torno da MO.

A análise dos trabalhos possibilitou traçar um mapeamento sobre as pesquisas que tratam da Memória Organizacional e analisar o desenvolvimento desse enfoque de pesquisa no decorrer do tempo - no que concerne ao número de publicações e autores que mais publicaram sobre o assunto. Além disso, foi possível conhecer as produções técnico-científicas realizadas por vários pesquisadores da área.

A partir desta pesquisa, podemos inferir que a MO tem o propósito de garantir e resguardar o conhecimento criado durante a vida da organização. Desse modo, não é possível conceber a Memória Organizacional dissociada do Conhecimento Organizacional, assim como implica afirmar que a MO tem um papel fundamental nos processos e nas práticas de Gestão do Conhecimento. 


\section{Financiamento}

O presente trabalho foi realizado com apoio da Coordenação de Aperfeiçoamento de Pessoal de Nível Superior - Brasil (CAPES), código de financiamento 001 .

\section{Referências}

ABECKER, A. et al. Toward a technology for organizational memories. IEEE: Intelligent Systems and their Applications, Los Angeles, v. 13, n. 3, p. 40-48, 1998.

ALMEIDA, M. B. Um modelo de ontologias para representação da memória organizacional. 2006. Tese (Doutorado em Ciência da Informação) - Programa de Pós-Graduação em Ciência da Informação, Universidade Federal de Minas Gerais, Belo Horizonte, 2006.

ALMEIDA, M. B.; PORTO, R. M. A. B. Manutenção de expertise: uma abordagem interdisciplinar baseada em aprendizado, conhecimento e memória organizacionais. Informação \& Sociedade: estudos, João Pessoa, v. 2, n. 24, p. 19-33, 2014.

ARAÚJO, C. A. A. Uma história intelectual da ciência da informação em três tempos. Revista Analisando em Ciência da Informação, João Pessoa, v. 5, n. 2, p. 10-29, jul./dez. 2017.

ARAÚJO, C. A. A. Fundamentos da Ciência da Informação: correntes teóricas e o conceito de informação. Perspectivas em Gestão \& Conhecimento, João Pessoa, v. 4, n. 1, p. 57-79, jan./jun. 2014.

ATWOOD, M. E. Organizational memory systems: challenges for information technology. In: HAWAII INTERNATIONAL CONFERENCE ON SYSTEM SCIENCES, 35., 2002, Big Island. Proceedings... Big Island: IEEE, 2002. p. 919-927.

BARDIN, L. Análise de conteúdo. Lisboa: Edições 70, 2011. 229 p.

BELlOTTO, H. L. Arquivos permanentes: tratamento documental. 2. ed. Rio de Janeiro: FGV, 2004. 320 p.

BOSI, E. Memória e sociedade: lembrança de velhos. 3. ed. São Paulo: Companhia das letras, 1994. 
CERANTE, L. L.; SANTOS, E. G. Gestão do conhecimento: Um estudo para facilitar sua implantação nas empresas. 2000. Projeto final de curso - Instituto de Matemática, Universidade Federal do Rio de Janeiro, Rio de Janeiro, 2000.

CHOO, C. W. A organização do conhecimento: como as organizações usam a informação para criar significado, construir conhecimento e tomar decisões. São Paulo: SENAC, 2006.

CONKLIN, J. Designing organizational memory: preserving intellectual assets in a knowledge economy. [S.I.]: CogNexus Institute, 2001.

CRIPPA, G. Memória: geografias culturais entre história e ciência da informação. In: MURGUIA MARANON, E. I. (Org.). Memória: um lugar de diálogo para arquivos, bibliotecas e museus. São Carlos: Compacta, 2010. p. 79110.

DAMANTE, N. Conhece-te a ti mesmo: entender a história como elemento de responsabilidade social conduz empresas e organizações à auto-análise. Revista Comunicação Empresarial, São Paulo, v. 14, n. 52, p. 28-35, 2004.

DUARTE, E. N. Análise da produção científica em gestão do conhecimento: estratégias metodológicas e estratégias organizacionais. 2003. Tese (Doutorado em Administração) - Universidade Federal da Paraíba, João Pessoa, 2004.

FIEDLER, M.; WELPE, I. How do organizations remember? The influence of organizational structure on organizational memory. Organization Studies, Brussels, v. 31, n. 4, p. 381-407, 2010.

FREIRE, P. S. et al. Memória organizacional e seu papel na gestão do conhecimento. Revista de Ciências da Administração, Florianópolis, v.14, n. 33, p. 41-51, ago. 2012.

HATAMI, A.; GALLIERS, R. D.; HUANG, J. Exploring the impacts of knowledge (re)use and organizational memory on the effectiveness of strategic decisions: a longitudinal case study. In: HAWAII INTERNATIONAL CONFERENCE ON SYSTEM SCIENCE, 36., 2003, Wailea. Proceedings... o. 2003.

JACKSON, P. An Exploratory Survey of the Structure and Components of Organizational Memory. Becoming virtual: Knowledge Management and Transformation of the Distributed Organization, 2007. 89 p.

JARDIM, J. M. A invenção da memória nos arquivos públicos. Ciência da Informação, Brasília, v. 25, n. 2, p. 1-13, 1995.

KE, W.; WEI, K. K. Organizational learning process: its antecedents and consequences in enterprise system implementation. Journal of Global Information Management, Hershey, v. 14, n.1, p. 1-22, 2006. 


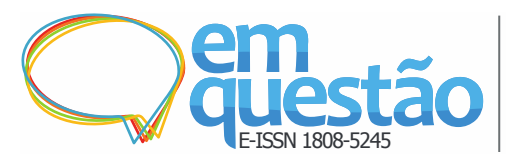

Memória Organizacional na Ciência da Informação: desvendando relações com o Conhecimento

Ryan Aramis de Brito Feitoza, Laiana Ferreira de Sousa, Ilka Maria Soares Campos e Emeide Nóbrega Duarte

LEHNER, F.; MAIER, R. K. How can organization memory theories contribute to organizational memory systems? Information Systems Frontiers, Dordrecht, v. 2, n. 3/4, p. 277-298, 2000.

LOUREIRO, E. C. Conhecimento e memória na Casa de Oswaldo Cruz/Fiocruz: reflexões e elementos para constituição de iniciativas de memória organizacional. 2016. Dissertação (Mestrado em Ciência da Informação) - Programa de Pós-Graduação em Ciência da Informação, Instituto Brasileiro de Informação em Ciência e Tecnologia, Rio de Janeiro, 2016.

MACEDO, N. A. M. Criando uma arquitetura de memória corporativa baseada em um modelo de negócio. 2003. Tese (Doutorado em Informática) Programa de Pós-Graduação em Informática, Pontifícia Universidade Católica do Rio de Janeiro, Rio de Janeiro, 2003.

MENEZES, E. M. de. Estruturação da memória organizacional de uma instituição em iminência de evasão de especialistas: um estudo de caso na COHAB. 2006. Dissertação (Mestrado em Gestão do Conhecimento e Tecnologia da Informação) - Programa de Pós-Graduação em Gestão do Conhecimento e Tecnologia da Informação, Universidade Católica de Brasília, Brasília, 2006.

MOLINA, L. G.; VALENTIM, M. L. P. Memória Organizacional, Memória Corporativa e Memória Institucional: discussões conceituais e terminológicas. Revista Educación e Investigación en Ciencia de la Información de Iberoamérica y el Caribe, Marília, v. 1, n. 1, p. 262-276, enero/marzo 2011.

MORESI, E. A. D. Memória organizacional e gestão do conhecimento. In: TAPARANOFF, K. (Org.). Inteligência, Informação e Conhecimento em corporações. Brasília: IBICT, 2006. p. 277-302.

NASSAR, P. Questões de memória. One Voice, [S.1.], 1 jun. 2009. Entrevista concedida à Camila Amorin.

NONAKA, I.; TAKEUCHI, H. Criação de conhecimento na empresa: como as empresas japonesas geram a dinâmica da inovação. 20. ed. Rio de Janeiro: Elsevier, 2007.

NONAKA, I.; TAKEUCHI, H. Gestão do conhecimento. Porto Alegre: Bookman, 2008.

POLLAK, M. Memória e identidade social. Estudos Históricos, Rio de Janeiro, v. 5, n. 10, p. 200-202, 1992.

RAO, R. D.; ARGOTE, L. Organizational learning and forgetting: the effects of turnover and structure. European Management Review, Milan, v. 3, p. 77-85, 2006. 
SANTOS, J. L. S.; URIONA-MALDONADO, M.; SANTOS, R. N. M. dos. Mapeamento das publicações acadêmico-científicas sobre memória organizacional. In: ENCONTRO NACIONAL DA ASSOCIAÇÃO NACIONAL DE PÓS-GRADUAÇÃO E PESQUISA EM ADMINISTRAÇÃO, 35., 2011, Rio de Janeiro. Anais... Rio de Janeiro: Enanpad, 2011. p. 1-17.

SARACEVIC, T. Ciência da Informação: origem, evolução e relações.

Perspectivas em Ciência da Informação, Belo Horizonte, v. 1, n. 1, p. 41-62, jan./jun. 1996.

SPILLER, A.; PONTES, C. C. C. Memória organizacional e reutilização do conhecimento técnico em uma empresa do setor eletroeletrônico no Brasil.

Revista Brasileira de Gestão de Negócios, São Paulo, v. 9, n. 25, p. 96-108, set./dez. 2007.

STEIN, E. W. Organization memory: review of concepts and recommendations for management. International Journal of Information Management, Malvern, v. 15, n. 1, p. 17-32, 1995.

WALSH, J. P.; UNGSON, G. R. Organizational memory. The Academy of Management Review, Briarcliff Manor, v. 16, n. 1, p. 57-91, 1991.

YAGUI, L. M. Memória organizacional: proposta para implantação em uma instituição de ensino superior. Florianópolis: UFSC, 2003. Dissertação (Mestrado em Engenharia de Produção) Programa de Pós-Graduação em Engenharia de Produção - Universidade Federal de Santa Catarina, Florianópolis, 2003.

\title{
Organizational Memory in Information Science: unraveling relationships with Organizational Knowledge
}

\begin{abstract}
This paper seeks to analyze the concepts of Organizational Memory through the scientific production published in the Base de dados de Periódicos em Ciência da Informação (Database of journal articles in Information Science), in order to understand its correlation to the Organizational Knowledge. Methodologically, it's characterized as an exploratory and descriptive documentary research with a qualitative-quantitative approach. For the analysis and organization of the data, the procedure used was the content analysis, following the thematic analysis technique, considering: authors who stood out in the production of research on the subject; distribution of published articles on Organizational Memory per year; Indexed journals in the database which publishes articles articles on the subject; main keywords addressed by the analyzed works and, finally, the analysis of the Organizational Memory concepts so as to understand its relations to the Organizational Knowledge. The results allow to infer that there was an increase in interest in studying the
\end{abstract}


organizational structure of companies, Thus demonstrating the need to expand researches involving the culture and memory of organizations. The research also made it possible to verify that the concepts of Organizational Memory present dialogical relations tho the Organizational Knowledge, allowing to conclude that both themes have correlations in the methodological, conceptual and practical senses.

Keywords: Organizational Memory. Organizational Knowledge. Scientific production. Information Science.

Recebido: 10/02/2018

Aceito: 19/06/2018

${ }^{1}$ CONKLIN, J. Designing organizational memory: preserving intellectual assets in a knowledge economy. [S.I.]: CogNexus Institute, 2001. Apud Cerante e Santos (2000).

${ }^{2}$ HUBER, G.P. A Theory Of The Effects Of Advanced Information Technologies. The Academy of Management Review, Briarcliff Manor, v. 15, n. 1, p. 47-71, 1990. Apud Ke e Wei (2006).

${ }^{3}$ WALSH, J. P.; UNGSON, G. R. Organizational memory. The Academy of Management Review, Briarcliff Manor, v. 16, n. 1, p. 57-91, 1991. Apud Ke e Wei (2006).

${ }^{4}$ O TOOLE, P. The role of organizational memory in organizational learning: a case study (1999). Apud Almeida (2006). 